\title{
Biologia reprodutiva de populações de Ocimum selloi Benth.
}

FACANALI, R. ${ }^{1,3}$; CAMPOS, M.M.S. ${ }^{3}$; POCIUS, O. ${ }^{2}$; MING, L.C. ; SOARES-SCOTT, M.D. ${ }^{3}$; MARQUES, M.O.M. ${ }^{3^{*}}$ ${ }^{1}$ Faculdade de Ciências Agronômicas, UNESP/Campus de Botucatu. Caixa Postal 237. 18610-307-Botucatu-SP, Brasil ${ }^{2}$ Departamento de Ecologia, Instituto de Biociências/USP. Rua do Matão, Travessa 14, no 321, Cidade Universitária. CEP 05508-900-São Paulo-SP, Brasil ${ }^{3}$ Laboratório de Produtos Naturais - Centro de P\&D de Recursos Genéticos Vegetais. Instituto Agronômico (IAC). Caixa Postal 28, 13.012-970-Campinas-SP, Brasil * mortiz@iac.sp.gov.br

\begin{abstract}
RESUMO: Entre as plantas nativas de uso medicinal no Brasil, encontra-se Ocimum selloi Benth., planta anual herbácea da família Lamiaceae que ocorre nas regiões Sudeste e Sul do país. Este trabalho avaliou os aspectos da biologia floral (estrutura floral, floração e frutificação) e mecanismos reprodutivos de Ocimum selloi em quatro populações oriundas das regiões de Piquete e Apiaí, Estado de São Paulo, Camanducaia, Estado de Minas Gerais, e Colombo, Estado do Paraná. O período de antese teve início às 11 horas e término às 15 horas, com o clímax de floração às 13 horas, sendo a temperatura pouco importante neste processo. A viabilidade do pólen foi alta nas quatro populações. A espécie é autocompatível, formando frutos e sementes tanto em polinização livre quanto em autopolinização espontânea, o que mostra uma grande versatilidade reprodutiva da espécie, garantindo a variabilidade genética. A germinação das sementes também foi alta nas quatro populações.
\end{abstract}

Palavras-chave: Ocimum selloi, biologia reprodutiva, biologia floral, plantas medicinais

\begin{abstract}
Reproductive biology of Ocimum selloi Benth. populations. Among the medicinal plants native to Brazil, Ocimum selloi Benth., an herbaceous annual plant of the Lamiaceae family, occurs in the southeastern and south regions of the country. This work evaluated flower biology aspects (flower structure, flowering and fructification) and reproductive mechanisms of four O. selloi populations from Piquete and Apiaí regions, São Paulo State; Camanducaia, Minas Gerais State; and Colombo, Paraná State. Anthesis started at 11:00 a.m. and finished at 3:00 p.m., with flowering climax at 1:00 p.m., and temperature was slightly important in this process. Pollen viability was high in all four studied populations. This species is self-compatible, forming fruits and seeds under both free pollination and spontaneous self-pollination, which indicates it has a great reproductive versatility, assuring genetic variability. Seed germination was also high in all four populations.
\end{abstract}

Key words: Ocimum selloi, reproductive biology, flower biology, medicinal plants

\section{INTRODUÇÃO}

O Brasil é o país com a maior diversidade vegetal do mundo, contando com mais de 55.000 espécies catalogadas (Dias, 1996), sendo que muitas destas apresentam potencial de uso medicinal e aromático, como é o caso de Ocimum selloi Benth. (Lamiaceae).

A espécie Ocimum selloi Benth. é uma planta anual herbácea, nativa das regiões Sudeste e Sul do Brasil, popularmente conhecida como elixir paregórico, anis, alfavaquinha e "atroveram" (Martins, 1998), apresentando propriedades antiespasmódica, antinflamatória, antidiarréica e antiulcerogênica, propriedades estas comprovadas por testes préclínicos (Vanderline et al., 1994; Cola et al., 2003), obtida por extrativismo e produtora de óleos essenciais. As caracterizações genética e química de populações de Ocimum selloi oriundas dos estados de São Paulo, Paraná e Minas Gerais, realizadas por Facanali $(2004 ; 2008)$, mostraram divergência genética e variação na composição química dos óleos essenciais em função das regiões de origem.

O conhecimento da biologia reprodutiva

Recebido para publicação em 24/02/2008

Aceito para publicação em 17/10/2008

Rev. Bras. PI. Med., Botucatu, v.11, n.2, p.141-146, 2009. 
fornece indícios sobre como os genes são recombinados e mantidos pela espécie para a perpetuação de sua variabilidade genética natural, base do seu continuo potencial evolutivo (Sebbenn et al., 1999), sendo assim essencial para o desenvolvimento de programas de melhoramento genético e compreensão do processo de domesticação de plantas (Silva et al., 2001).

Diversos fatores ecológicos e genéticos podem afetar os padrões de reprodução, resultando na ocorrência de endogamia nas populações e na variação temporal e espacial das taxas de cruzamento, mecanismos de incompatibilidade (Murawski \& Hamrick, 1992) e padrões de florescimento, tais como, duração do período de florescimento, sincronia e densidade de indivíduos com flores (Fuchs et al., 2003; Hall et al., 1996; Murawski \& Hamrick, 1991).

De modo geral, as plantas exibem diversidade de sistemas reprodutivos e para a compreensão, além das análises habituais de polinização controlada e natural, também é importante a investigação minuciosa de aspectos como número de grãos de pólen por antera, viabilidade dos grãos de pólen, crescimento do tubo polínico, razão de produção de grãos de pólen por óvulo, dimensões do ovário, determinação do período de receptividade do estigma, dentre outros (Cruden \& Miller-Ward, 1981).

O sucesso de programas de melhoramento genético e de conservação depende do completo conhecimento do processo reprodutivo. Sendo assim, o presente trabalho teve como objetivo estudar a biologia floral de Ocimum selloi, avaliando sua morfologia floral, o período de abertura das flores, a viabilidade de grãos de pólen, o sistema reprodutivo e a produção de frutos e sementes, em condições de polinização livre e autopolinização espontânea.

\section{MATERIAL E MÉTODO}

O estudo foi realizado entre junho de $2005 \mathrm{e}$ janeiro de 2006 no Instituto Agronômico (IAC), Campinas, Estado de São Paulo. As plantas de quatro populações de Ocimum selloi Benth. oriundas das regiões de Colombo (Estado do Paraná, 2517'00"S e 49¹5'00"WO), Apiaí (Estado de São Paulo, 2430'37"S e 48 $50^{\circ} 23^{\prime \prime} \mathrm{WO}$ ), Piquete (Estado de São Paulo, $22^{\circ} 36^{\prime} 49^{\prime \prime} S$ e $45^{\circ} 10^{\prime} 43^{\prime \prime W O}$ ) e Camanducaia (Estado de Minas Gerais, 22.45'30's e $56^{\circ} 09^{\prime} 00^{\prime \prime} \mathrm{WO}$ ), foram cultivadas em vasos de 5 litros com terra vermelha em telado de náilon (tipo Sombrite ${ }^{\circledR}$, com $70 \%$ de permeabilidade luminosa) no Centro de Pesquisa e Desenvolvimento de Recursos Genéticos Vegetais do Instituto Agronômico (IAC). Os testemunhos botânicos coletados foram depositados no herbário do Instituto Agronômico de Campinas - IAC, e registrados sob os números IAC
44394, IAC 44524, IAC 49328 e IAC 49329.

A descrição da morfologia externa foi realizada com base em material vivo segundo a chave analítica proposta por Bentham (1832) a partir da análise de 40 flores (10 flores de cada população) sob estereomicroscópio. Foram determinados o número, a disposição e a coloração de cada um dos verticilos florais.

Para a determinação da antese foram feitas observações diárias durante quatro meses (Agosto a Novembro/2005) em 4 inflorescências determinadas aleatoriamente em cada população. As inflorescências foram marcadas, com fita colorida, na fase de botões imaturos, e a contagem das flores abertas foi feita em intervalos de uma hora, amostrados ao longo do dia, das 10 às 17 horas. $A$ temperatura referente a cada horário foi observada $e$ registrada.

O número de grãos de pólen por flor e a estimativa da viabilidade polínica foram determinados a partir de botões florais em pré-antese. Foram coletados 10 botões florais ao acaso, de diferentes indivíduos, para cada uma das populações. As anteras (quatro por botão) foram retiradas e os grãos de pólen frescos transferidos para lâminas de microscopia. A análise da viabilidade foi realizada segundo a técnica de coloração de Alexander (1980), com a amostra de 300 (trezentos) grãos de pólen para cada lâmina.

Para o estudo do sistema reprodutivo foram analisadas a produção e a maturação de frutos por flores submetidas a polinização natural e autopolinização espontânea. Foram escolhidos 10 ramos florais, ao acaso, com botões imaturos para cada uma das quatro populações estudadas. A polinização livre foi avaliada em ramos marcados que não foram ensacados. Para verificar a ocorrência de autopolinização espontânea os ramos foram isolados em sacos de polietileno providos de poros, segundo descrito por Ormond \& Pinheiro (1974); após três semanas os sacos foram retirados e os frutos formados contados.

Para a análise de produção de frutos e sementes foram discriminadas as seguintes variáveis: total de frutos produzidos, total de sementes produzidas e quantidade de flores que não geraram frutos (FR0), que geraram frutos com uma semente (FR1), duas sementes (FR2), três sementes (FR3) e quatro sementes (FR4).

A avaliação da germinação das sementes foi realizada em amostras com 200 sementes de cada uma das quatro populações, sem qualquer tratamento. Foram realizados dois experimentos com um mês de duração. Experimento I: germinação em caixas de germinação (tipo "gerbox") usando substrato comercial organo-mineral para olericultura, Plantmax $®$ Hortaliças HA, mantido sob telado de náilon (tipo 
Sombrite ${ }^{\circledR}$, com $70 \%$ de permeabilidade luminosa), com temperatura e umidade ambiente não controlada. Experimento II: germinação de sementes em placa de Petri em câmara de crescimento com temperatura controlada $\left( \pm 27^{\circ} \mathrm{C}\right)$.

Os visitantes florais foram observados in loco de agosto a novembro de 2005. Os insetos foram capturados em frascos de vidro para posterior identificação.

Foram realizadas análises de variância (Anova) e análise estatística de Pearson qui-quadrado (Zar, 1996) para verificar associações entre as variáveis.

\section{RESULTADOE DISCUSSÃO}

As flores de Ocimum selloi são agrupadas em inflorescências cimosas três a três com nectário na base de cada grupo de três flores, completas, hermafroditas, cíclicas e hipóginas. O cálice é pentâmero, gamossépalo, persistente e encobre o tubo da corola. A corola é bilabiada, gamopétala, pentâmera, zigomorfa de coloração do roxo ao róseo. O androceu é epipétalo, com quatro estames; as anteras são livres, dorsifixas, com deiscência rimosa ou longitudinal. O gineceu é gamocapelar, com estigma bífido e estilete ginobásico. O ovário é súpero, tetralobado, com disco nectarífero na base. Os frutos são tetraquênios, produzindo um número máximo de quatro sementes por fruto, amarronzadas e ligeiramente alongadas.

Para todas as populações de Ocimum selloi avaliadas, o processo de antese teve início às 11 horas, com aumento no número de flores abertas no intervalo das 12 às 13 horas, clímax de floração às 13 horas, decaindo no intervalo das 13 às 14 horas e cessando a partir das 15 horas (Figura 1), neste período, de agosto a novembro de 2005, a temperatura variou de 18 a $40^{\circ} \mathrm{C}$, mas não foi um fator significativo. Neste processo o fator mais importante foi o horário $(p=0,000)$, seguido do fator população $(p=0,020)$. Amaral et al. (1999) com Ocimum selloi e Almeida et al. (2004) em Ocimum officinalis, obtiveram resultados discordantes dos observados neste trabalho, e concluíram que o processo de antese nestes táxons estaria intimamente relacionado com a temperatura e a luminosidade.

A produtividade polínica média por flor, para cada população, foi de 641 para Colombo/PR, 666 para Apiaí/SP, 579 para Piquete/SP e 628 para Camanducaia/MG.

A Tabela 1 mostra as médias e a porcentagem do número de grãos de pólen viáveis para cada população. A viabilidade do pólen de 0 . selloi em pré-antese variou de 79 a $87 \%$, sendo considerada alta, porém a produtividade polínica foi baixa (média de 628 grãos por flor). Brasileiro \&

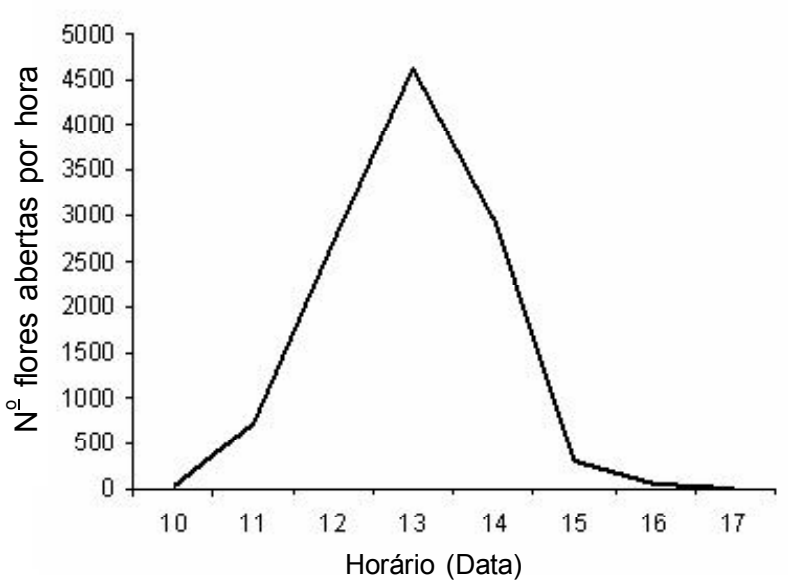

FIGURA 1. Número de flores abertas por hora nas populações de Ocimum selloi Benth.

Amaral (2007) caracterizando o sistema reprodutivo de acessos de Ocimum canum, 0 . officinalis e 0 . selloi, obtiveram uma produtividade polínica média de, respectivamente, 1015, 920 e 1165 grãos de pólen por flor, com uma viabilidade de $97 \%$, 96\% e $98 \%$. Almeida et al. (2004), estudando os mecanismos reprodutivos de Ocimum officialis, obtiveram uma porcentagem média de $97 \%$ de viabilidade do pólen, com produtividade de 3823 grãos de pólen de flores de 10 diferentes indivíduos na pré-antese.

Segundo Flanklin et al. (1995), a viabilidade polínica é fundamental para a análise da fertilidade do pólen, podendo auxiliar no desenvolvimento de programas de melhoramento genético. No presente estudo, a viabilidade polínica de $O$. selloi foi considerada alta, sendo este, portanto, um fator importante para o melhoramento genético da espécie.

Os experimentos em situação de polinização livre e autopolinização espontânea demonstram que ocorreu um aumento na produção de frutos quando as inflorescências foram ensacadas, sendo este acréscimo mais acentuado para as populações de Apiaí/SP e Camanducaia/MG $(p=0,007$ e $p=0,000)$ (Figura 2). A produção de sementes também aumenta para estas duas populações quando as inflorescências são ensacadas, porém de forma menos acentuada que o aumento na produção de frutos. Para as outras populações, Colombo/PR e Piquete/SP, a produção de sementes diminuiu quando as inflorescências foram ensacadas (Figura 3).

No estudo da influência da manipulação experimental (ensacamento) sobre a distribuição do número de sementes por fruto para cada população, verificou-se que, em condições naturais (não ensacadas), a distribuição de freqüência para as classes de frutos (FR0, FR1, FR2, FR3 e FR4) apresentou dependência significativa (qui-quadrado $\left.\left(X^{2}\right)=28,66 ; p=0,005\right)$ em relação à população de origem das inflorescências analisadas. Em condições experimentais de ensacamento (autopolinização) o 
TABELA 1. Média, desvio-padrão e freqüência da viabilidade polínica das populações de Ocimum selloi.

\begin{tabular}{lcccc}
\hline \multicolumn{1}{c}{ População } & Média & $\%$ & Desvio Padrão & $\mathrm{n}^{\star}$ \\
\hline Apiai/SP & 262,90 & 87,64 & 13,56 & 10 \\
Camanducaia/MG & 240,10 & 80,03 & 26,77 & 10 \\
Colombo/PR & 249,60 & 83,20 & 19,13 & 10 \\
Piquete/SP & 238,40 & 79,47 & 25,77 & 10 \\
\hline
\end{tabular}

${ }^{*} \mathrm{n}=$ número de botões florais; \% = freqüência da viabilidade polínica

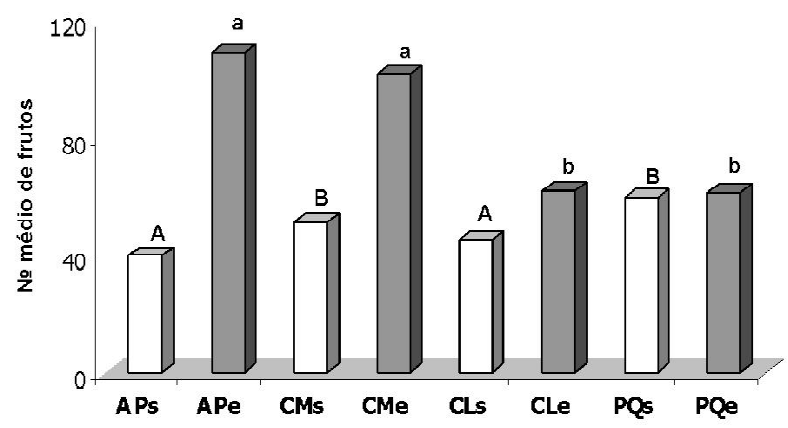

FIGURA 2. Produção média de frutos em situação de polinização livre e autopolinização espontânea em Ocimum selloi. Onde: APs = Apiaí/Não Ensacado, APe = Apiaí/ Ensacado, $\mathrm{CMs}=$ Camanducaia/Não Ensacado, $\mathrm{CMe}=$ Camanducaia/Ensacado, CLs = Colombo/NãoEnsacado, $\mathrm{CLe}=$ Colombo/Ensacado, $\mathrm{PQs}=$ Piquete/Não Ensacado e $P Q e=$ Piquete/Ensacado. * Letras maiúsculas indicam diferenças entre si a $5 \%$ de probabilidade pelo teste de Tukey em situação de polinização livre; * Letras minúsculas indicam diferenças entre si a $5 \%$ de probabilidade pelo teste de Tukey em situação de autopolinização espontânea.

mesmo não ocorre $\left(X^{2}=11,49 ; p=0,487\right)$, ou seja, quando as inflorescências foram ensacadas, a distribuição de freqüências entre as classes de frutos foi mais homogênea, aumentando a freqüência de flores que não produziram frutos (sem semente - FR0) e diminuindo a freqüência de frutos com quatro sementes (FR4) para todas as populações.

Estes resultados podem explicar o fato de que dentro de uma mesma população (Apiaí/SP, Camanducaia/MG), quando as inflorescências são ensacadas, há um aumento significativo no total de frutos sem diferença significativa no total de sementes (produção), conforme demonstrado nas Figuras $1 \mathrm{e}$ 2. Ou seja, apesar de produzirem um número maior de frutos estes não têm produção máxima de sementes, sugerindo que esta possa ser uma estratégia reprodutiva da planta investindo em maior produção de frutos para compensar a diminuição na produção de sementes, já que quando as inflorescências são ensacadas o número de frutos com quatro sementes diminui drasticamente.

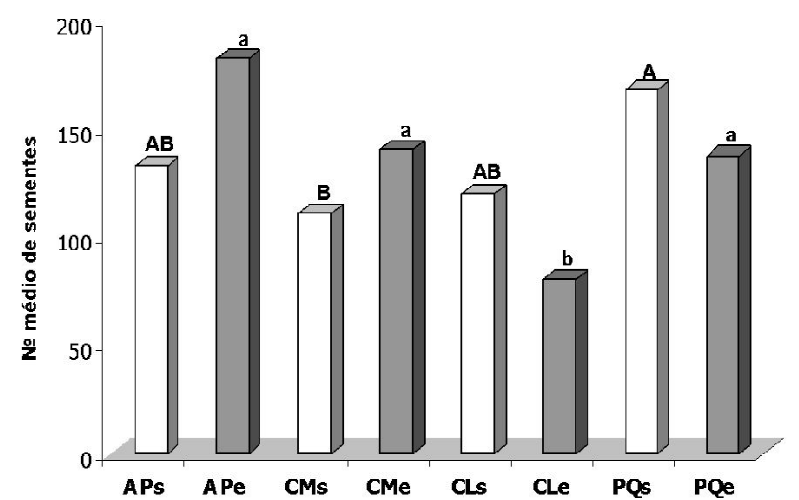

FIGURA 3. Produção média de sementes em situação de polinização livre e autopolinização espontânea em Ocimum selloi. Onde: APs = Apiaí/Não Ensacado, $\mathrm{APe}=\mathrm{Apiaí} /$ Ensacado, $\mathrm{CMs}=$ Camanducaia/Não Ensacado, $\mathrm{CMe}=$ Camanducaia/Ensacado, $\mathrm{CLs}=$ Colombo/NãoEnsacado, CLe = Colombo/Ensacado, $\mathrm{PQs}=$ Piquete/Não Ensacado e $\mathrm{PQe}=$ Piquete/ Ensacado. * Letras maiúsculas indicam diferenças entre si a $5 \%$ de probabilidade pelo teste de Tukey em situação de polinização livre; * Letras minúsculas indicam diferenças entre si a $5 \%$ de probabilidade pelo teste de Tukey em situação de autopolinização espontânea.

Portanto, os resultados referentes ao sistema reprodutivo demonstraram que o que ocorre nas populações de Ocimum selloi é uma combinação de sistemas reprodutivos, havendo cruzamentos e autofertilizações, ou seja, a espécie apresenta um sistema de reprodução misto, podendo se reproduzir tanto por autogamia quanto por alogamia. Resultados semelhantes foram obtidos nos trabalhos realizados por Silva et al. (2008) com O. canum e Nation et al. (1992) nas espécies $O$. basilicum e 0 . selloi, que também apresentaram sistema de reprodução misto podendo reproduzir-se tanto por polinização cruzada (alogamia) como por autopolinização (autogamia).

Em Ocimum selloi a autopolinização ocorre na pré-antese com a flor ainda fechada, indicando compatibilidade, desta forma ocorre cleistogamia nas flores de 0 . selloi. No entanto, como a fertilização só ocorre com a flor aberta (pós-antese) é possível a ocorrência de fecundação cruzada. Estas observações são concordantes com Amaral et al. (1999), que observaram cleistogamia nas flores de $O$. selloi, alta compatibilidade, autopolinização e autofecundação para uma população oriunda de Viçosa/MG.

As flores abertas de $O$. selloi foram visitadas principalmente por Apis mellifera, polinizador mais comum do gênero Ocimum (Darrah, 1980). Desta forma, mediante possíveis falhas na autopolinização a flor teria a fertilização garantida, pois após a 
autopolinização e abertura da flor, o estigma permanece receptivo (Amaral, 1998).

Segundo Allard (1971) e Paterniani (1974), a autogamia permite à população adaptação às condições ambientais. Porém, a alogamia garante maior flexibilidade adaptativa à espécie, por proporcionar maior variabilidade genética.

A autogamia permite ainda, a formação de linhagens puras para caracteres de importância econômica (Paterniani, 1974), interessante para a realização de cruzamentos nas gerações posteriores de $O$. selloi. Já a alogamia possibilita a manutenção ou aumento do vigor híbrido das espécies pela ocorrência de novas combinações de genes codificadores de caracteres de interesse agronômico (Paterniani, 1974), como por exemplo, a produção de óleos essenciais, que constituem um dos mais importantes grupos de matéria-prima para as indústrias de alimentos, farmacêutica, perfumaria e afins.

Os resultados referentes ao número total de sementes germinadas e não germinadas e a freqüência de germinação nos Experimentos I e ll estão representados na Tabela 3. A germinação das sementes no Experimento I ocorreu após duas semanas da semeadura, e o teste de Pearson quiquadrado mostrou que a taxa de germinação é dependente da população $\left(X^{2}=15,31 ; p=0,002\right)$. Já no Experimento II, as sementes germinaram após três dias da semeadura e, neste caso, não houve dependência da população na taxa de germinação $\left(X^{2}=4,738 ; p=0,192\right)$.

Através do teste de independência entre freqüência de germinação (germinado $x$ não germinado) e condição experimental de germinação (Experimento I e II) por população, pode-se verificar que ocorreu dependência entre o tipo de experimento e a freqüência de germinação de três populações: Colombo/PR (qui-quadrado $=20,757 ; p=0,000$ ), Apiaí/ $\mathrm{SP}$ (qui-quadrado $=30,571 ; p=0,000$ ) e Piquete/SP (qui-quadrado $=18,816 ; p=0,000$ ). Nestas populações o local de germinação teve efeito significativo em relação à freqüência de germinação, sendo esta maior quando as sementes são colocadas para germinar em placas de Petri, sob papel de filtro e água destilada, em estufa com temperatura controlada $\left( \pm 27^{\circ} \mathrm{C}\right)$. Já a população de Camanducaia/MG não apresentou dependência, mostrando freqüências de germinação semelhantes em ambos os experimentos.

\section{CONCLUSÃO}

Diante do exposto, pode-se concluir que o período de antese teve início às 11 horas e término às 15 horas, com o clímax de floração às 13 horas, sendo a temperatura pouco importante neste processo, já que a viabilidade do pólen e a germinação das sementes foram altas nas quatro populações.

A espécie Ocimum selloi apresenta uma combinação de sistemas reprodutivos, formando frutos e sementes tanto em polinização livre quanto em autopolinização espontânea, mostrando uma grande versatilidade reprodutiva da espécie, garantindo assim a variabilidade genética, essencial para sua evolução e futuros programas de melhoramento genético.

\section{AGRADECIMENTO}

À Fapesp pelo auxílio financeiro (processo no 02/14005-0) e pela concessão da bolsa da Marina M. S. de Campos (processo no 05/54962-1), a CAPES pela concessão da bolsa de Doutorado da Roselaine Facanali. À Rauly Moretti e Dra Neiva Izabel Pierozzi

TABELA 3. Total de sementes germinadas e freqüência de germinação das populações de Ocimum selloi Benth.

\begin{tabular}{ccccc}
\hline População & Experimento & $\begin{array}{c}\text { Total de } \\
\text { sementes }(\mathbf{n})\end{array}$ & $\begin{array}{c}\text { Total de sementes } \\
\text { germinadas }\end{array}$ & $\begin{array}{c}\text { Freqüência de } \\
\text { germinação }\end{array}$ \\
\hline CAM & I & 200 & 192 & 0,96 \\
CAM & II & 200 & 194 & 0,97 \\
PIQ & I & 200 & 177 & 0,88 \\
PIQ & II & 200 & 198 & 0,99 \\
COL & I & 200 & 173 & 0,86 \\
COL & II & 200 & 197 & 0,98 \\
API & I & 200 & 169 & 0,84 \\
API & II & 200 & 199 & 0,99 \\
\hline
\end{tabular}

API - Apiaí/SP; CAM - Camanducaia/MG; COL - Colombo/PR e PIQ - Piquete/SP; I = germinação em caixas de germinação (tipo "gerbox"); II = germinação de sementes em placa de Petri. 
pelo apoio técnico do Centro de P\&D de Recursos Genéticos Vegetais do Instituto Agronômico.

\section{REFERÊNCIA}

ALEXANDER, M.P. Versatile stain for pollen fungi, yeast and bacteria. Stain Technology, v.55, p.13-8, 1980. ALLARD, R.W. Princípios do melhoramento genético de plantas. São Paulo: Edgard Blucher, 1971. 381p. ALMEIDA, O.S. et al. Estudo da biologia floral e mecanismos reprodutivos do alfavacão, Ocimum officinalis L. visando o melhoramento genético. Acta Scientiarum Biological Sciences, v.26, n.3, p.343-8, 2004.

AMARAL, C.F.L. Floral biology and isoenzymatic variability in Ocimum selloi Benth. Genetics and Molecular Biology, v.21, n.4, p.579, 1998.

AMARAL, C.L.F.; ALMEIDA, E.C.; CASALI, V.W.D. Biologia floral e mecanismos de reprodução da alfavaca (Ocimum selloi Benth.). In: SEMINÁRIO MINEIRO DE PLANTAS MEDICINAIS, 1., 1999, Viçosa. Anais... Viçosa: Ed. da UFV, 1999. p.1-11.

BENTHAM, G. Ocimum. In: Labiatarum genera et species. 1832. London: Ridgeway \& Sons, 1932. p.119.

BRASILEIRO, B.P.; AMARAL, C.L.F. Caracterização do sistema reprodutivo de acessos de Ocimum spp. (Lamiaceae) do banco de germoplasma de plantas medicinais da UESB - Bahia, Brasil. Magistra, v.19, n.4, p.333-6, 2007.

COLA, M. et al. Óleo essencial de Ocimum selloi Benth.: atividade antiulcerogênica. Documentos IAC, n.74, p.120, 2003.

CRUDEN, R.W.; MILLER-WARD, S. Pollen-ovule ratio, pollen size, and the ratio of stigmatic area to the pollenbearing area of the pollinator: an hypothesis. Evolution, v.35, p.964-74, 1981.

DARRAH, H.H. The cultivated basils. Independence: Buckeye Printing, 1980. 40p.

DIAS, B.F.S. A implementação da convenção sobre diversidade biológica no Brasil: desafios e oportunidades. Campinas: André Tosello, 1996. 10p.

FACANALI, R. Caracterização da diversidade genética e da composição química do óleo essencial de populações de Ocimum selloi Benth. 2004. 93p. Dissertação (Mestrado em Agronomia - Horticultura) Faculdade de Ciências Agronômicas, Universidade Estadual Paulista, Botucatu.

FACANALI, R. Estudo da biologia reprodutiva, diversidade genética e química de populações de Ocimum selloi Benth. 2008. 129p. Tese (Doutorado em Agronomia - Horticultura) - Faculdade de Ciências
Agronômicas, Universidade Estadual Paulista, Botucatu. FLANKLIN, F.H.C.; LAWRENCE, M.J.; FLANKLIN-TONG, V.E. Cell and molecular biology of self-incompatibility in flowering plants. International Review of Cytology, n.158, p.1-62, 1995.

FUCHS, E.J.; LOBO, J.A.; QUESADA, M. Effects of forest fragmentation and flowering phenology on the reproductive success and mating patterns of the tropical dry forest tree Pachira quinata. Conservation Biology, v.17, n.1, p.149-57, 2003.

HALL, P.; WALKER, S.; BAWA, K.S. Effect of forest fragmentation on genetic diversity and mating system in a tropical tree, Pithecellobium elegans. Conservation Biology, v.10, n.3, p.757-68, 1996.

MARTINS, E.R. Estudos em Ocimum selloi Benth.: isoenzimas, morfologia e óleo essencial. In: MING, L.C. et al. (Eds.). Plantas medicinais, aromáticas e condimentares: avanços na pesquisa agronômica. Botucatu: UNESP, 1998. p.97-126.

MURAWSKI, D.A.; HANRICK, J.L. The effect of the density of flowering individuals on the mating systems of nine tropical tree species. Heredity, v.67, n.2, p.16774, 1991.

MURAWSKI, D.A.; HAMRICK, J.L. The mating system of Cavanillesia platanifolia under extremes of floweringtree density: a test of predictions. Biotropica, v.24, n.1, p.99-101, 1992

NATION, G.R.; JANICK, J.; SIMON, E.J. Estimation of outcrossing in basil. HortScience, v.27, n.11, p.1221-2, 1992.

ORMOND, W.T.; PINHEIRO, M.C.B. Contribuição ao estudo biossintético e ecológico de Petiveria alliaceae L. Revista Brasileira Biologia, v.34, n.1, p.123-42, 1974. PATERNIANI, E. Evolução dos sistemas dos vegetais. Ciência e Cultura, v.26, n.5, p. 476-81, 1974.

SEBBENN, A.M. et al. Variação genética entre e dentro de populações de amendoim - Pterogyne nitens. Scientia Florestalis, n.56, p.29-40, 1999. Disponível em: <http://www.ipef.br/publicacoes/scientia/nr56/ cap02.pdf $>$. Acesso em: 03 set. 2008.

SILVA, A.B. et al. Biologia floral e mecanismos reprodutivos de Ocimum canum Sims (Lamiaceae). Revista Biotemas, v.21, n.2, p.33-40, 2008.

SILVA, R.M.; GERHARD BANDEL, M.I.F.F.; MARTINS, P.S. Biologia reprodutiva de etnovariedades de mandioca. Scientia Agrícola, v.58, n.1, p.101-7, 2001.

VANDERLINE, F.A.; COSTA, E.A.; D'ANGELO, L.C.A. Atividades farmacológicas gerais e atividade antiespasmódica do extrato etanólico de Ocimum selloi Benth. (elixir paregórico). In: SIMPÓSIO DE PLANTAS MEDICINAIS DO BRASIL, 13., 1994, Fortaleza. Resumos... Fortaleza: UFC, 1994. p.103. ZAR, J.H. Biostatistical analysis. New Jersey: Prentice Hall, 1996. 662p. 